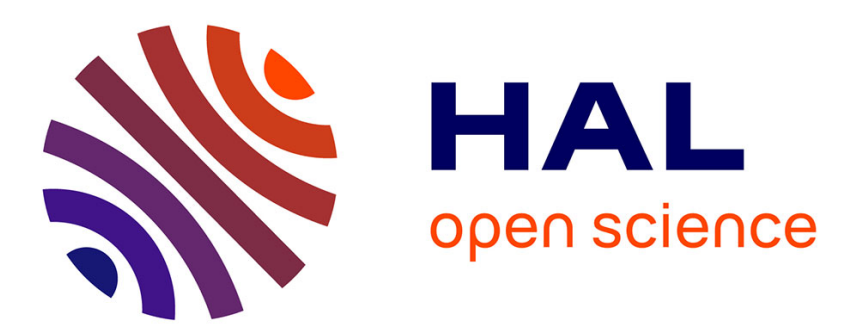

\title{
Comparison Between Two Semi-Analytical Methods for Computing the Radiation Characteristics of a Fabry-Perot Cavity
}

\author{
Halim Boutayeb
}

\section{- To cite this version:}

Halim Boutayeb. Comparison Between Two Semi-Analytical Methods for Computing the Radiation Characteristics of a Fabry-Perot Cavity. Microwave and Optical Technology Letters, 2006, 48 (8), pp. 1654 - 1656. 10.1002/mop.21692 . hal-00149261

\section{HAL Id: hal-00149261 https://hal.science/hal-00149261}

Submitted on 25 May 2007

HAL is a multi-disciplinary open access archive for the deposit and dissemination of scientific research documents, whether they are published or not. The documents may come from teaching and research institutions in France or abroad, or from public or private research centers.
L'archive ouverte pluridisciplinaire HAL, est destinée au dépôt et à la diffusion de documents scientifiques de niveau recherche, publiés ou non, émanant des établissements d'enseignement et de recherche français ou étrangers, des laboratoires publics ou privés. 


\title{
Comparison Between Two Semi-Analytical Methods for Computing the Radiation Characteristics of a Fabry-Perot Cavity
}

\author{
Halim Boutayeb \\ INRS-EMT, 800 rue de la Gauchetiere, Montréal Québec H5A 1K6, Canada. \\ Email: boutayeb@inrs-emt.uquebec.ca. Fax: (514)-875-0344
}

Abstract - In this contribution, two semi-analytical methods are compared for computing the radiation characteristics of a Fabry-Perot cavity excited by an internal current line source. One method uses the leaky wave theory and the other method uses a ray analysis. Compared to the conventional ray method, the first method offers more accurate results without increasing computing time. A full wave method is used as a reference.

Key words: Periodic structures; Fabry-Perot cavity; Directive antenna, leaky wave antenna 


\section{Introduction}

For the analysis of directive antennas based on a Fabry-Perot cavity, the ray method has been used [1-3]. For instance, a cavity composed of a ground plane and a Partially Reflecting Surface (PRS) has been considered in [1]. In [2], a detector has been embedded inside a crystal, and in [3], the directivity of a Fabry-Perot cavity antenna has been analysed for different frequencies. The proposed semi-analytical method gives rapid results and allows interesting analysis [3]. In this letter, we compare this method to a another semi-analytical method based on leaky wave theory, in order to obtain the radiation patterns of a Fabry-Perot cavity excited by a line source. The leaky wave based method gives more accurate results than those obtained by the ray method without increasing processing time.

\section{Fabry-Perot type cavity Structure}

In this work, the structure shown in Figure 1 is considered. It is composed of a line source and a PRS at each side of the source. The PRS surface is composed of infinite long metallic wires, and it is characterized by the following parameters: the wire diameter $a$, the transversal period $P_{t}$, and the length $L_{R}$. The surface characteristics are represented in terms of the reflection and transmission coefficients $r$ and $t$, which are calculated at the normal direction and for an infinite long surface using FDTD method.

\section{Ray method}

In this method, it is assumed that the source is sending infinite number of rays in all directions $\theta$. The complex transmission coefficient, defined by the amplitude of the wave outside the cavity and normalized by the amplitude of the incident wave, is obtained by adding the successive reflected and transmitted rays. Neglecting the angular dependency of $r$ and $t$, this coefficient can be written as [3]:

$$
T(f, \theta)=\frac{t \exp (-j k D \cos (\theta) / 2)}{1-r \exp (-j k D \cos (\theta))}
$$

where $k$ is the wave number. From this equation, it can be noted that the coefficient $T$ can describe the behaviour of the structure as a function of frequency and angle. 


\section{Leaky wave method}

The leaky wave radiation of a Fabry-Perot type antenna has been studied in [4], and its radiation pattern is expressed as:

$$
F(\theta) \approx \frac{-\cos (\theta)}{k_{0}^{2} \cos ^{2}(\theta)+\gamma_{x}{ }^{2}}
$$

where $k_{0}$ is the wave number at the resonance frequency and $\gamma_{x}$ is the $x$ component of the propagation constant. It is shown now that the coefficient $\gamma_{x}$ can be evaluated as a function of the PRS reflection coefficient. Considering the transmission line model of the structure, shown in Figure 2, the coefficient $z_{s}$ is the normalized impedance that models one PRS, and it can be written as a function of $r: z_{s}=-(r+1) / 2 r$. Referring to Figure $2, Z^{+}$and $Z^{-}$ represent the impedance seen at each side of the doted line. The leaky wave transverse

resonance condition imposes $Z^{+}+Z^{-}=0$ [4], which can be written for the present structure as

$$
\frac{1-\frac{1}{1+2 z_{s}} \exp \left(-2 \gamma_{x} D\right)}{1+\frac{1}{1+2 z_{s}} \exp \left(-2 \gamma_{x} D\right)}=\frac{-z_{s}}{z_{s}+1}
$$

After inverting this equation and writing $z_{s}$ as a function of $r$, the coefficient $\gamma_{x}$ can be expressed as

$$
\gamma_{x}=\ln (r) / D
$$

This relation is used in Eq. (2) to obtain the radiation pattern of the structure.

\section{Numerical results and discussion}

To demonstrate the validity of the proposed approach, numerical simulations were carried out for calculating the PRS characteristics and the radiation pattern of the structure illustrated in Figure 1. The following parameters $D=80 \mathrm{~mm}, a=2 \mathrm{~mm}$ are fixed and the two cases $P_{t}=10 \mathrm{~mm}$ and $P_{t}=40 \mathrm{~mm}$ are considered. Numerical results for the coefficient $|T|$ of these structures, at $\theta=0^{\circ}$, are shown in Figure 3. It can be noted that the resonant frequency occurs at $f_{0}{ }^{\prime}=1.81 \mathrm{GHz}$, where $r \approx 0.99 \exp (j 3.04)$, for $P_{t}=10 \mathrm{~mm}$, and at 
$f_{0}=1.44 \mathrm{GHz}$, where $r \approx 0.76 \exp (j 2.44)$, for $P_{t}=40 \mathrm{~mm}$. For the first case, Figure 4 shows the radiation patterns calculated by the FDTD method, the hybrid FDTD-ray method (using Eq. (1) with $k=k_{0}{ }^{\prime}$ ) and the hybrid FDTD-leaky wave method (using Eqs. (2) and (4)). For the second case, Figure 5 gives the radiation patterns at the resonance frequency obtained with different methods. From these patterns, it can be concluded that the hybrid FDTD-leaky wave method is more close to the FDTD method than the hybrid FDTD-ray method. As a result, the accuracy of the hybrid FDTD-ray method decreases when the transversal period enhance.

\section{Conclusion}

In this letter, two semi-analytical methods for analysing the radiation patterns of Fabry-Perot cavities internally excited have been compared. The leaky wave based method produces more accurate results compared to the ray method without increasing processing time. 


\section{REFERENCES}

1. G.V. Trentini, Partially reflecting sheet arrays, IRE Trans Antennas Propagat 4 (1956), 666-671.

2. B. Temelkuran, E. Ozbay, J.P. Kavanaugh, G. Tuttle, and K.M. Ho, Resonant cavity enhanced detectors embedded in photonic crystal, Appl Phys Lett 72 (1998), 2376-2378.

3. H. Boutayeb, K. Mahdjoubi, A.C. Tarot and T.A. Denidni, Directivity of an antenna embedded inside a Fabry-Perot cavity: Analysis and Design, Microw Opt Technol Lett 48 (2006), 12-17.

4. R.E. Collin, Analytical solution for a leaky-wave antenna, IRE Trans Antennas Propagat 10 (1962), 561-565

5. L.O. Goldstone and A.A. Oliner, Leaky-Wave Antenna I: Rectangular Waveguides, IRE Trans Antennas Propag 7 (1959), 307-319 


\section{Figure Captions:}

FIG. 1: Line source inside Fabry-Perot cavity composed of two periodic surfaces of metallic wires

FIG. 2: Transmission line model of the Fabry-Perot cavity based structure

FIG. 3: $|T|$ coefficient at $\theta=0^{\circ}$ (Eq. (1)) for a structure with the following parameters: - -

$--D=80 \mathrm{~mm}, \mathrm{a}=2 \mathrm{~mm}$ and $P_{t}=40 \mathrm{~mm} ;-D=80 \mathrm{~mm}, \mathrm{a}=2 \mathrm{~mm}$ and $P_{t}=10 \mathrm{~mm}$.

FIG. 4: Radiation pattern at $f_{0}{ }^{\prime}=1.81 \mathrm{GHz}$ for $D=80 \mathrm{~mm}, a=2 \mathrm{~mm}$ and $P_{t}=10 \mathrm{~mm}$ : hybrid FDTD-ray method $\left(|T|\right.$ coefficient at $\left.f=f_{0}{ }^{\prime}\right)($ Eq. (1))

- - - hybrid FDTD-leaky wave method (Eqs. (2) and (4))

FDTD method, $L_{R}=9630 \mathrm{~mm}$

FIG. 5: Radiation pattern at $f_{0}=1.44 \mathrm{GHz}$ for $D=80 \mathrm{~mm}, a=2 \mathrm{~mm}$ and $P_{t}=40 \mathrm{~mm}$ :

…....... hybrid FDTD-ray method ( $|T|$ coefficient at $\left.f=f_{0}\right)$ (Eq. (1))

- - - - hybrid FDTD- leaky wave method (Eqs. (2) and (4))

- FDTD method, $L_{R}=1040 \mathrm{~mm}$ 
FIG. 1

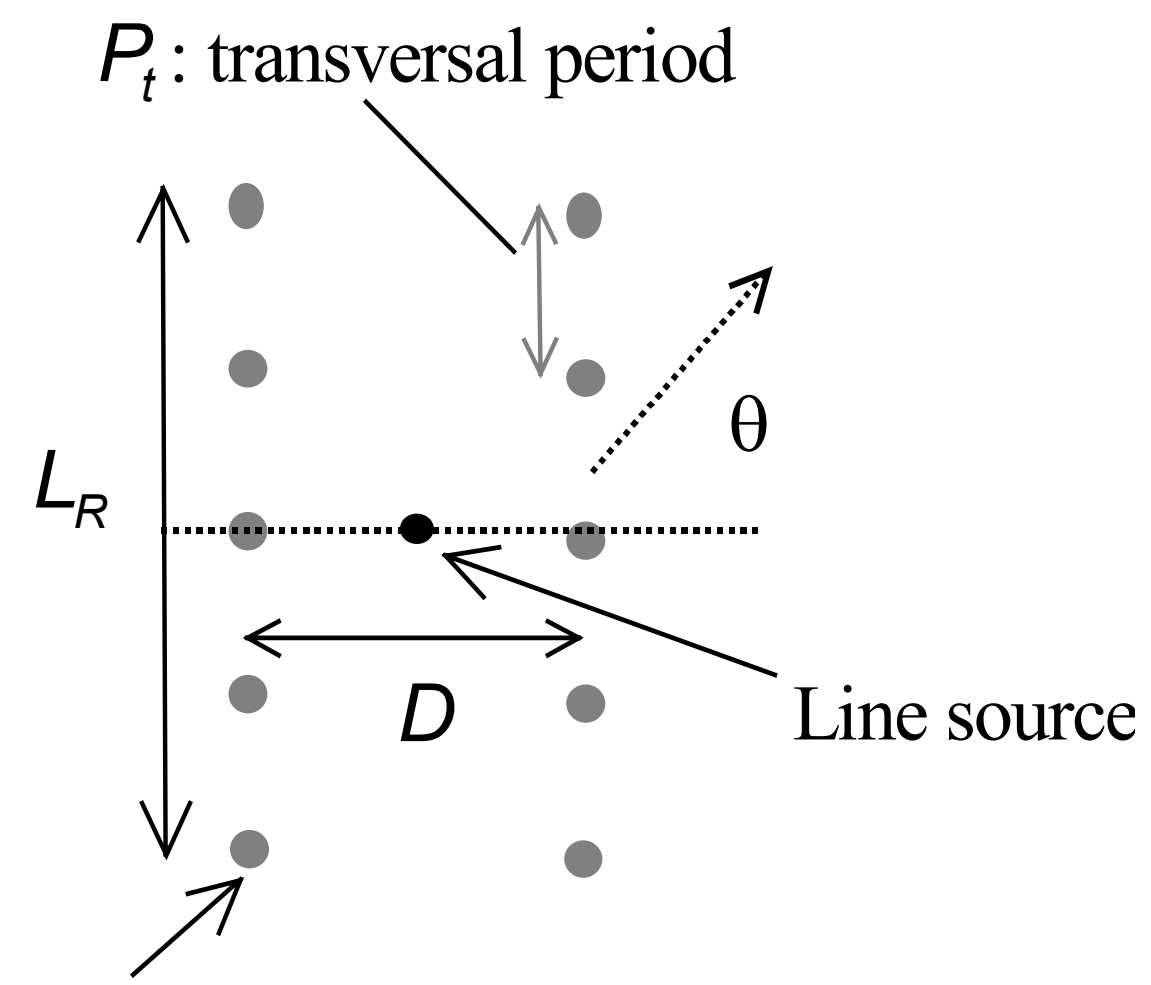

Metallic wires of diameter $a$ 
FIG. 2

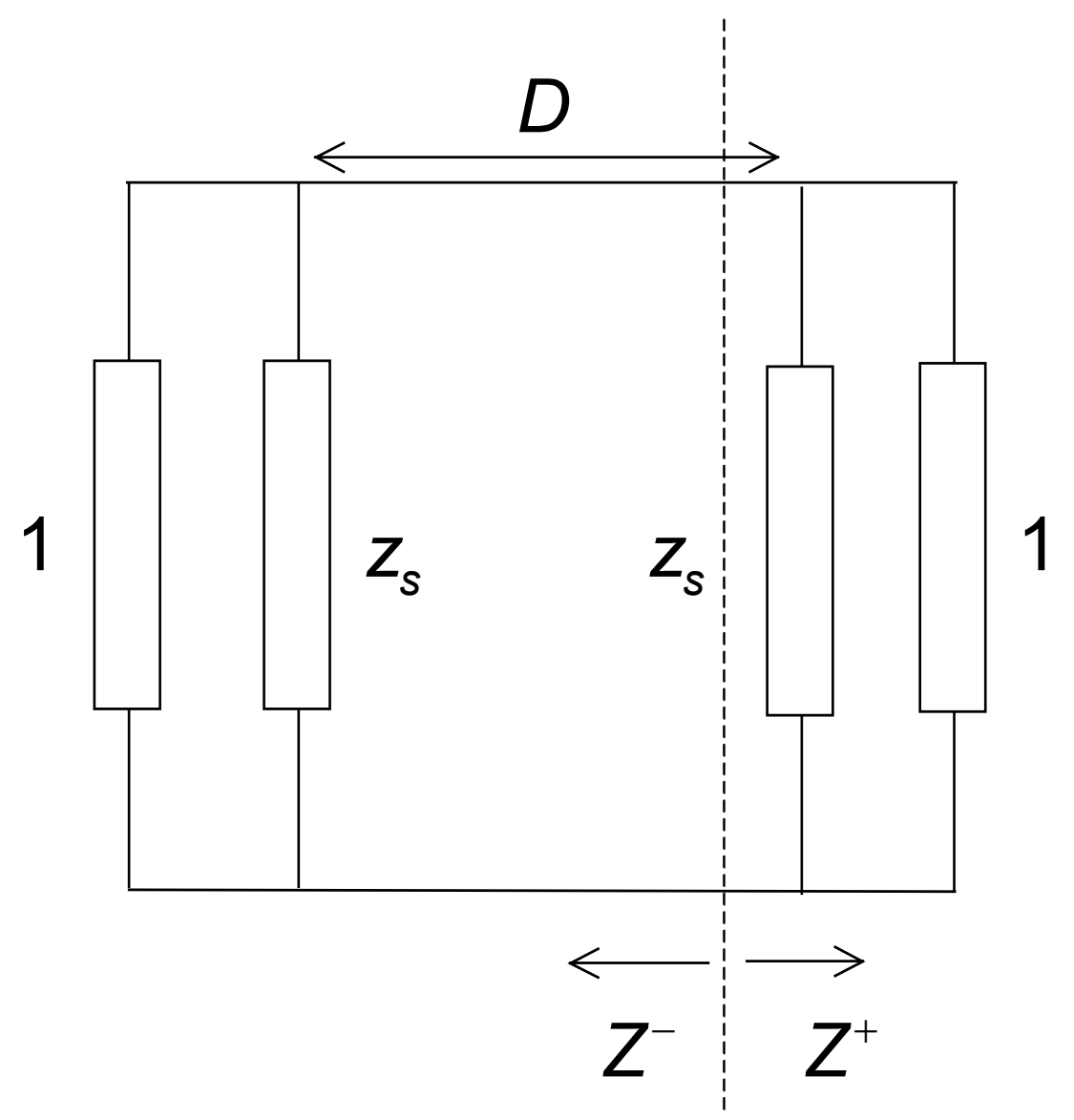


FIG. 3

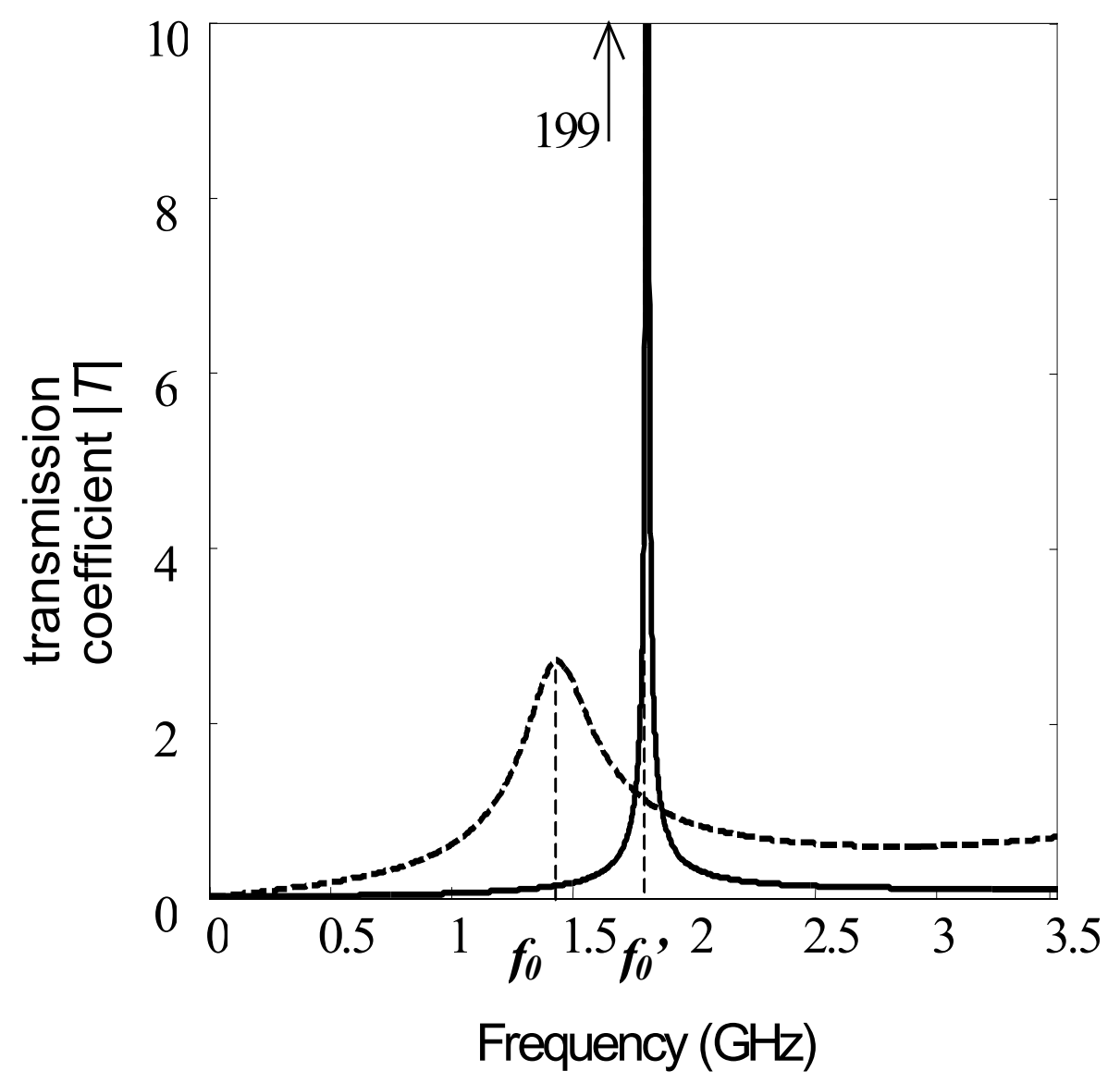


FIG. 4

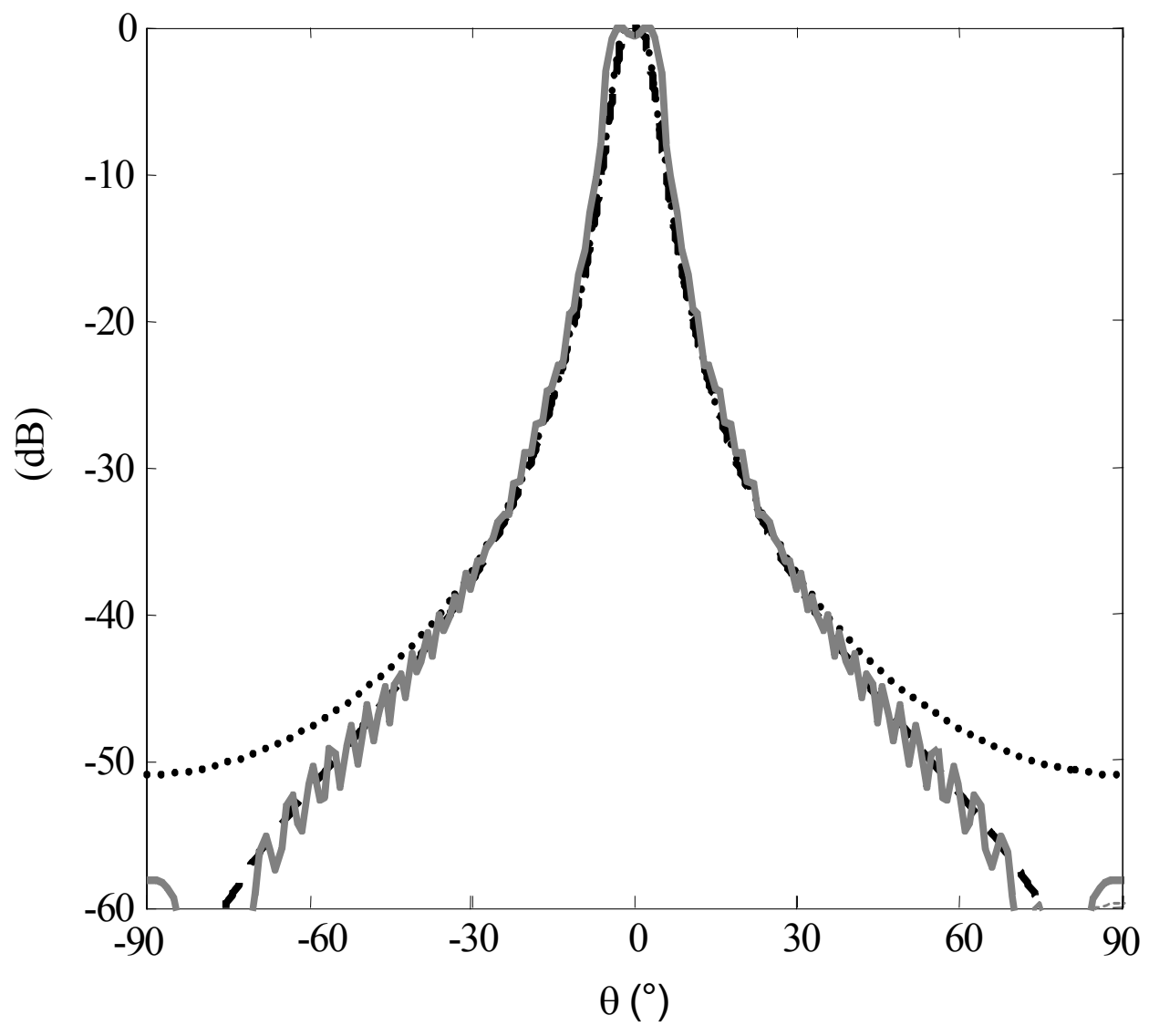


FIG. 5

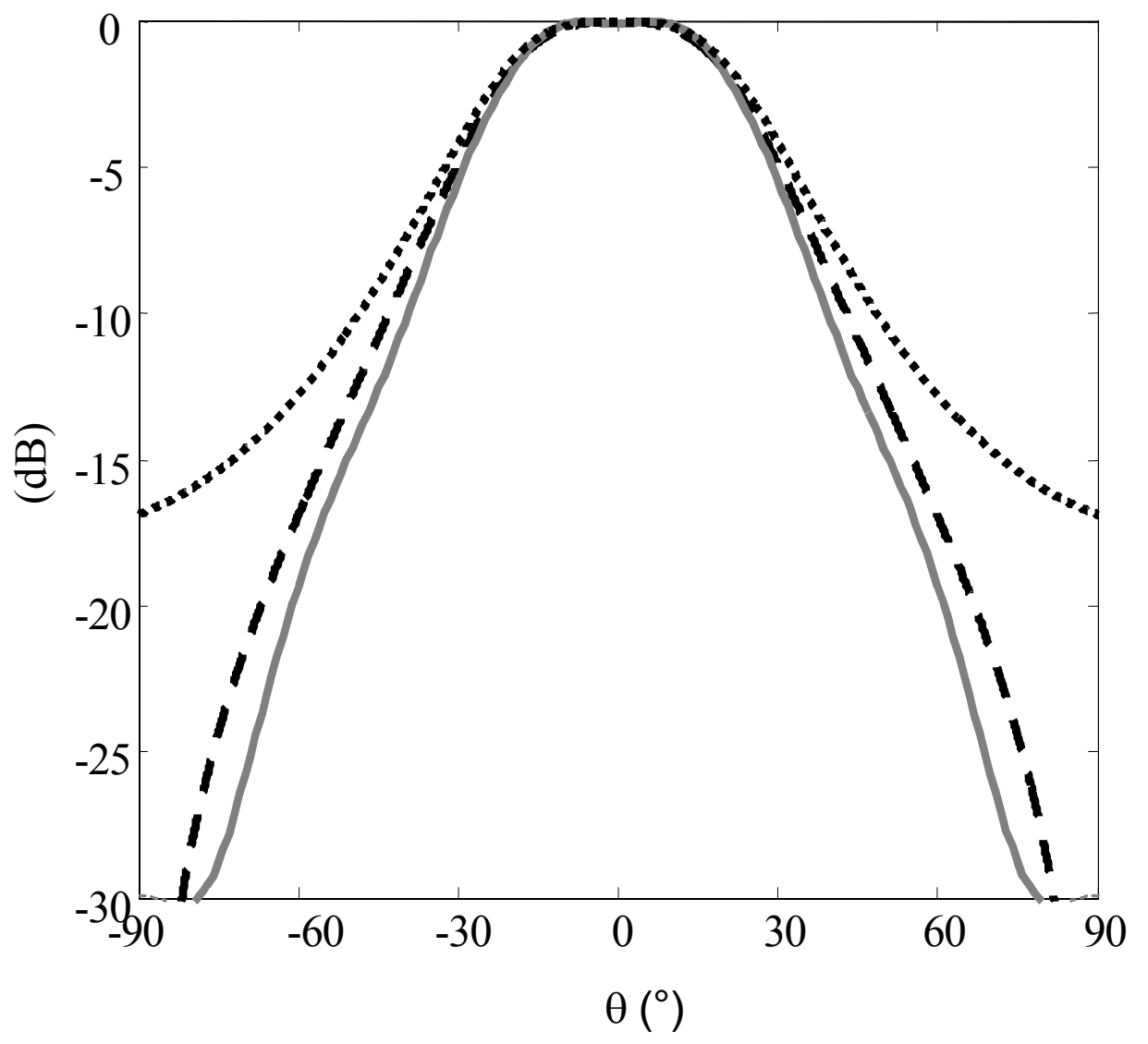

